\title{
Being an identity prop: some ethical implications
}

\author{
By Joel Busher (School of Development Studies, University of East Anglia)
}

During recent fieldwork in Namibia I noticed that the people I worked with often took care to arrange our public encounters so that onlookers did not interpret our relationship in ways that might be inconvenient. I was cast as a friend, colleague, employer, customer, acquaintance. My presence created opportunities for the extension of people's "repertoire of identities" (Cinnirella 1998) in both desirable and undesirable directions, and their choreography of our public encounters can be seen as part of their "impression management" (Davis 1986). Observing this process generated opportunities for me to gain insight into the way that people in the research sites negotiated social representations of identity and attributed values to particular social categories, such as volunteer, friend, namesake, NGO-worker, person living with HIV and so forth. However, finding myself playing allocated roles also raised ethical issues, two of which I discuss in this article: 1) Did my presence and participation give apparent endorsement to leaders and support claims about the legitimacy of social hierarchies? 2) Did my involvement with HIV/AIDS projects and the consequent crystallisation of my repertoire of identities threaten to undermine colleagues' and respondents' impression management? I conclude by reflecting on the limitations of my ethical approach at the outset of this research. I recommend that researchers be wary of the narrow perspective of research ethics that can emerge during the ethical clearance procedure, and that they continue to re-visit and adapt their ethical approach whilst in the field.

\section{Introduction: identity narratives}

I recruited David as a research assistant when I started my fieldwork. (David is a pseudonym, as are all of the names used in this paper.) He had moved the short distance from the research site into town seven years earlier but continued to visit his family regularly. On our first field visit in 2007 he was asked, "Have you joined that church, the one where they walk around one black and one white?" David smiled and said no, we were doing research about community groups. He explained to me that people assumed we were Jehovah's Witnesses because we were a white and a black person walking together and I was carrying a bag. Even several months later, one of David's friends drove past us whilst we were in a community-group meeting. We noticed he had a flat tyre and tried to wave him down, but he drove on. David's friend later explained that he knew his tyre was flat but thought we were calling him to church and he didn't want to publicly refuse to join us. As we walked, another person enquired, "Are you looking for orphans?" David explained that we were not registering orphans and vulnerable children (OVC); we were from a university, not the government or an NGO. However, the idea that we were conducting research without subsequently setting up either a church or a project seemed difficult to situate for many of the people we spoke with. As we arrived back at his new house a neighbour called out, "So now you're moving with your white friend?" David laughed back, "Of course!" At the end of the week as I was about to pay him, he requested that 
we walk a bit away from his house so that his neighbours didn't see the transaction: "I've told them I'm a volunteer. If they know how much I'm getting they will be coming to me for credit and they will just eat my money."

When I arrived in the field I was interested in social identities from an analytical and a methodological perspective. I wanted to look at how residents of the research sites negotiated social representations of identity as they encountered new institutions through Namibia's "fight against HIV/AIDS" (Office of the President 2004). Having immersed myself in methodology and methods textbooks, I had also considered the way in which aspects of $m y$ identity and the identity of my research assistants might affect my research activities and the data that I would generate. In particular I had thought about how "impression management" strategies (Davis 1986) could help me to find ways of bridging the differences between me and my respondents (Howarth 2002): the clothes I would wear, the language I would speak, my mode of transport, how I would greet people, whom I should speak to first, and other such details.

However, my early observations of public encounters with David suggested that I needed to think more carefully about the linkages between these methodological and analytical issues. The narratives that people in the research sites created about me were not just about me, but about the relationships between me and other people. The relational nature of the construction of my identity implied that representations of my identity could also be appropriated, interpreted and applied in the identity construction and negotiation taking place around others (Jovchelovitch 1996). Through this process I could become a sort of identity prop. I use the term "identity prop" in a similar way to Dunning (1999), to refer to a culturally meaningful object or action that can provide a reference point for categorisation and identification. Relationships with me could function in a similar way to other kinds of identity props, like clothes (Mookherjee 2001), language, or type of vehicle (Srivastava 2006).

This opened up a rich vein of observations about social relationships, the negotiation of social identities and the attribution of values to categories such as NGO-worker, friend, namesake, brother-in-law, volunteer and so forth. However, there were also ethical implications because the methodological question, "How do my respondents', my research assistants' and my identities affect the data that will be generated?" could now be inverted. I was also asking, "How does the process of data generation that I am undertaking affect my respondents', colleagues' and my repertoires of identities?"

In this paper I discuss this reformulated question and how it affected my approach to the subject of research ethics. I draw on Campbell and Jovchelovitch's (2000) discussion of social identities in relation to health and the social psychology of participation, in which they raise three core issues. Firstly, negotiated identities contribute to shape the parameters of individual aspirations and behaviours; secondly, the negotiation of social identities occurs within existing structures of power and can in turn contribute to the legitimisation and reproduction of hierarchies; and thirdly, notions of social identity are drawn upon in definitions of community boundaries, and therefore in discourses of inclusion and exclusion. The two ethical issues that I raise here relate to the second and third points. I will ask: 1) Did my presence and participation give apparent endorsement to leaders and support claims about the legitimacy of social hierarchies? 2) Did my involvement with HIV/AIDS projects and the consequent crystallisation of my repertoire of identities threaten to undermine colleagues' and respondents' efforts to construct and maintain identities that they considered to be desirable? I will not seek to "resolve" these issues, but I will 
conclude with some remarks about the limitations that they revealed in my ethical approach. I suggest that whilst navigating through the bureaucratic process of gaining ethical clearance I generated an ethical approach that operated around "certain narrow 'research-focused' criteria" (Langer 2005:5). Based on this, I recommend that researchers should seek to maintain a broader approach to research ethics and should re-visit their ethical approaches throughout their research.

\section{My research project}

I wanted to explore the ways in which people's experiences of a recent surge in the number of civil society organisations has interacted with social representations of civil participation, leadership, trust, and moral cohesion. In particular I was interested in the interaction between the involvement of these organisations in "the fight against HIV/AIDS" and the moral discourses that have evolved around them. I anticipated that people's sense of social identity would play an important role in shaping their relationship with the organisations and their discourses. For example, church elders might be less inclined to engage with organisations conducting sexual health outreach education, and men might less readily take on volunteer positions that entail performing traditionally female activities like childcare or care for the infirm.

The fieldwork was conducted in a medium-sized town in North-East Namibia, on the border with Angola. The population is estimated to be approximately 70,000, with the majority living in as-yet un-surveyed settlements around the periphery of the town. My research sites were situated in two of these settlements. I had previously worked in the town for Voluntary Service Overseas (VSO) and the Namibia Red Cross Society 18 months prior to conducting field research. I had also played football with a prominent local club and had been involved in a highly-publicised youth sport initiative. As such, I had established a fairly extensive social network. In choosing the research sites I avoided the settlement in which I had worked the most during this time for fear of being unable to shake off my former identity as "the Red Cross man".

I conducted field research over an 18-month period. During this time I worked with five research assistants. In most cases we worked together for between two to four months due to their other work and family commitments. I worked with David throughout the 18 months (and I have spoken with him about the content of this paper because, despite the name change, he could conceivably be identified based on the information provided.) In the first four months of fieldwork I made introductions, sought permission from the relevant authorities and conducted introductory interviews and observations. I then spent four months evaluating the research questions and methods and conducting some preliminary data analysis. In the second period of fieldwork I conducted on-going field observations; a randomly sampled household survey (33\% of the households); and a series of purposively sampled qualitative research activities: 80 minimally-structured life-history interviews; observation of 6 community-development initiatives; 62 institutional analyses based on the themes of trust, fairness, effectiveness, and participation; and 14 key informant interviews with persons who have played a major role in the local "fight against HIV/AIDS".

Prior to starting fieldwork I completed the university's ethical clearance procedure and formulated my ethical approach. This matter is not taken lightly at the University of East Anglia, and considerable effort has gone into ensuring that all research conducted by faculty members and students in the School of Development Studies 
meets recognised ethical standards. I sent a nine-page document to the Ethics Committee, in which I explained how I had reflected upon and would seek to manage the issues of physical and psychological risk to colleagues and respondents, consent, confidentiality, power relationships and coercion, and specific vulnerabilities associated with power imbalances in relation to gender, cultural practices and other salient social structures. My application was approved.

\section{Recognising myself as a viable identity prop}

As I started to generate data, I wanted to see how my early field observations fitted with the provisional analytical framework that I had constructed for my upgrade paper at the end of the first year of my PhD. I had grounded my analytical framework in Social Representations Theory (cf. Jovchelovitch 1996, Moscovici 1984, Wagner et al. 1999) and the assertion that identities and identity props, like other social representations, are anchored and objectified in situated discourses through their negotiation, use, contestation and extension. I therefore understood identities to be malleable and non-unitary, and at least in part constructed around whom we associate with and how we are associated with them (Schensul et al. 1999). This tied in with the notion that individuals have "repertoires of identities" (Cinnirella 1998) that at any time and place are subject to psychological and social limitations.

My early field experiences with David supported this understanding of social identities. I could trace how my identity was being negotiated and anchored through a series of interactions, understandings and what I perceived to be misunderstandings. People observed what I did, how I did it and whom I did it with, and then tried to fit that within existing interpretive frameworks. Previous visits from a white and a black person had been about Bibles and orphans, so it was logical to presume that we were interested in one or the other. I could also observe how limits were set around my repertoire of identities. For example, I could never be a "poor student" in my research sites as my student stipend was several times higher than the salary of all but a handful of the most senior civil servants and businessmen, and there was a general expectation that, as a white person, I would have access to reserves of cash hidden away somewhere. However, as the parameters to my repertoire of identities were fuzzy, I could employ impression management strategies in an effort to shape them to my liking. Whilst I could not be a poor student, I could distance myself from the urban economic elite by living a modest lifestyle: eating similar foods to people in the research site, not sporting expensive clothing, or socialising in the less up-market bars. Despite these efforts, my frequent encounters with local rumours and gossip reminded me that my impression management, and my explanations about who I was and what I was doing, had only a limited impact on the way in which I was described by others.

I could trace similar identity negotiation processes taking place around David and, as I became more attuned to the research environment, around other people with whom I was interacting. As my language skills improved and as I spent more time with respondents and other residents I heard myself being socially located in relation to known others within the research sites: I was the friend of one person, the employer of another, a customer to another. The social representation "Joel Busher" was being objectified through its use in propositions about relationships between other people and me. As part of a system of meaning, I could both be described through my 
relationships to others and could be a reference point with which to describe others: if Joel Busher was the friend of David, then David was the friend of Joel Busher.

I started paying greater attention to the impression management strategies deployed by others with regards to their relationship with me. David seemed adept at choreographing our public encounters so as to extend his repertoire of identities in ways that he considered desirable. As a youth, he had been part of a notorious gang at a time when there was a moderate level of violence in the settlement. In contrast with his youth, he had in recent years volunteered with three community-based organisations and in doing so portrayed himself as a "serious" and "active" member of the community. Describing somebody as "serious" and "active" was often used by respondents to denote a general civic-mindedness. His new position with me supported this narrative, and he made increasing contributions to community and group meetings that we attended. At the end of the week he would also often buy a round of drinks when we went to the bar, displaying generosity, adult independence and status (Fumanti 2002).

People's relationships with me were explained and presented in different ways, at different times and to different audiences. My collaboration in community projects would be extended into claims about friendship, or my engagement in reciprocity networks would be described as a mutual bond of duty. When one respondent died, I am told that his family confidently predicted that they would receive a contribution towards the funeral costs from me because I was close to them. Language was also used to emphasise aspects of our relationship that could be supportive of desired identity claims. Some older respondents of Angolan origin who arrived in Namibia during the 1960s and 1970s seemed to revel in the opportunity to speak Portuguese in public, and would often criticise what they described as Namibian ways of doing things, using language as a marker of their difference and, perhaps, our proximity.

Observing this ongoing choreography I could see that the contacts people had with me were not of some peculiar kind that could be quarantined away from the milieu of everyday social contacts. I was placed within local frames of reference and as such became a viable prop for identity construction and negotiation. Whilst this opened up some interesting avenues for investigation, I also found that it raised some ethical issues that went beyond the scope of the ethical approach that I had outlined prior to fieldwork.

\section{Endorsing leaders and legitimising hierarchies}

Did my presence and participation give apparent endorsement to leaders and support claims about the legitimacy of social hierarchies?

Much of my contact with organisations took place either through gatekeepers or with reference to their permission for me to communicate with other members of their organisation. People were rarely willing to provide information about an organisation unless they were one of the senior committee members, and if I wanted to speak to other members of an organisation I was usually told to first obtain permission through the organisation's leaders. This meant that in order to gain access to organisations I had to acknowledge and work within institutional hierarchies. It also meant that my relationship with the organisations and any inputs that I may have offered were mediated largely by those gatekeepers. They were then in a strong position to frame my involvement as a kind of support for the activities that they were carrying out. 
In one organisation with which I worked the management committee was failing to fulfil its responsibilities and there were rumblings of discontent among the rest of the group. The management committee was not holding meetings, the chairperson was frequently out of contact with the other committee members, the accounts had not been presented and the programme that they were responsible for was a long way behind schedule. However, my presence and occasional inputs helped the committee to maintain that they were "active" in some ways. In several meetings I heard myself quoted as corroboration for claims being made about how the organisation was performing. As such, I acted as a prop with which to support claims about good and effective leadership. Ethical reflection on this was made more pertinent by the fact that as an educated, foreign, white researcher I could be quite a sturdy prop due to my presumed expertise and connections.

In some cases my apparent endorsement of the leadership was quite direct. One group that I worked with was trying to establish a brick-making project. They asked me to help them submit a funding proposal. I agreed to help them identify donors and provided some linguistic help with the proposal. As part of the proposal it was necessary to nominate and write down the names of the committee. Prior to this meeting three people had acted as project leaders, but this was the first time that the committee had been formalised. My experience with another organisation suggested that this was a significant event for a nascent organisation. The other organisation had been initiated by an international volunteer five years earlier. Through the process of writing a constitution and writing down the names of a committee, a hierarchy was formally established that remained in place to the time of my research despite minimal inputs from a number of the committee members. When discussions about the activities of these members arose, reference would be made to the international volunteer who continued in absentia to occupy a position of authority as the founder of the organisation. For this reason I chose not to contribute to the discussion about who should occupy the senior positions in the brick-making project and I insisted that one of the group members should actually complete the form. However, merely by being present and by participating in the activity of producing the proposal I could be seen to have lent my support to the formalisation of the hierarchy and therefore to any future authority claims by the nominated individuals.

To some extent I do think that I acted as a prop to support claims about leadership and status, although I do not want to insinuate that there was mal-intent on the part of the leaders. In fact, I believe that the leaders of all the organisations that I observed were acting in what they saw as the best interest of their organisations. The ethical issue is that the nature of my relationship with organisations meant that people in leadership positions had greater control over the way that the social representation "Joel Busher" could be deployed, and therefore over who or what I could be said to support. This was a difficult issue to address directly, because I wanted to observe organisations and had no intention of seeking to instigate hierarchical change.

One measure that my research assistants and I pursued was to cultivate a "communityoriented" narrative about the nature of the research so that we could explain to people outside the management committees why we wanted to speak to them and not only the group leaders. We also sought to build relationships with a range of people in the community by creating opportunities to speak with them informally: at the shops, in the street, in a bar, or at their houses. I do not suggest that this resolved the issue. What it did was to build a broader base of interpersonal histories with residents, which 
made it easier to stop and talk to people in the street or pay a social visit at somebody's house. My hope is that this made me a less exclusive identity prop.

\section{My identity as a threat to respondents' impression management}

Did my involvement with HIV/AIDS projects and the consequent crystallisation of my repertoire of identities threaten to undermine colleagues' and respondents' impression management?

This question relates to the way in which socially negotiated identities have the potential to include or exclude individuals from social categories or groups. Whilst people I met often seemed quite happy, or at least unconcerned to be in some way associated with me, there were a number of instances in which proximity to me seemed to pose a threat to respondents' impression management. Perhaps not surprisingly, it was often my involvement with HIV/AIDS that appeared to be the issue. I suggest that as doubts arose about my identity and the nature of my research, a concern arose that this might somehow contaminate their repertoire of identities.

My research assistant and I first interviewed Hamutenya about a church programme for out-of-school youth. He encouraged us to contact him later during the research. Six months later his household was one of the households that we surveyed and he again provided answers and asked about how the project was progressing. Based on his age, gender and degree of involvement in community-based projects, we included him in the purposive sample for the life-history interviews. We visited him and made an appointment for an interview. The following week we went to our appointment to find that Hamutenya was about to leave the house to attend to some church business. I said that I was sorry and we re-arranged the appointment. Over the next month we made five visits to Hamutenya, each time failing to find a time to speak with him. After two of these visits my research assistant told me about an encounter he had had with Hamutenya at the hospital when he was collecting some data from the HIV/AIDS clinic. It happened shortly after we had made our first appointment with him. Apparently there had been an awkward greeting and then nothing more was said between them. My research assistant suggested that Hamutenya could be afraid to speak with us because he might think our research was really about HIV/AIDS. This was a plausible hypothesis given the association that people often made between white researchers, orphans and vulnerable children (OVC) and, consequently, HIV/AIDS. We did eventually manage to conduct an interview with Hamutenya. We did not raise the topic of HIV/AIDS because my research assistant and I agreed that to do so would be unfair. Most of our questions were about his political activism in the 1980s and changes in the way that decisions are made within the settlement. We also had a long discussion about the nature of the research project, during which we explained that we were interested in the way that community participation had been changing since Independence in 1990. The following month we arranged a final interview with him. We had no difficulty in arranging a time and he appeared considerably more relaxed than he had been in the previous interview.

One difference between this encounter with Hamutenya and the one that I will describe with Selina is that with Selina my possible identification with HIV/AIDS was raised very publicly and may therefore be considered to have been a more imminent risk to her repertoire of identities. 
Selina ran a small business selling food and drink where my research assistants and I would often bump into other people that we knew. Her business was on a main thoroughfare so we would meet Selina most days and exchange greetings. We had previously spoken with her about illness and had talked about HIV/AIDS in general terms. When we were trying to arrange our fourth interview with her there was a group of young men playing cards, two of whom we were friends with. As we arrived, one of them called out to us to ask what we were doing there. Selina suddenly looked distinctly uncomfortable. She didn't greet us; she busied herself putting food into containers and avoided eye contact. The young man who had called out to us was a prominent HIV/AIDS activist who provided free counselling to many people living with HIV/AIDS in the neighbourhood. My research assistant and I said that we were tired from walking and just wanted to sit down. We watched the card game for a short while and then left. When we met the young man a few days later, he asked how we had come to know "his client" Selina. The next time we visited Selina there was no card game and no audience. We sat in our usual seats in her bar and talked.

In both cases the temporary reluctance to be seen to have a relationship with me appears to arise from encountering my possible association with HIV/AIDS. My research assistant drew a revealing parallel between us and the government registered vehicle that was used to follow up people who had defaulted on their anti-retroviral treatment. He explained, "The neighbours will know what it means if there is a visit and people know that their neighbours will know what it means: there is somebody with the virus." Placing this within the social identities literature, I would argue that Hamutenya's and Selina's responses were ways of safeguarding the borders of their repertoires of identity in reaction to the reconfigured parameters of inclusion and exclusion emanating from my identity. Whereas participation in the research may previously have connoted inclusion in a group thought by a foreign researcher to have something interesting to say about life in the settlement, now it seemed that participation in the research could connote living with HIV. Inclusion in the group "people that are interviewed by Joel Busher" would under these new conditions mean identification with a group that continues to be stigmatised.

Unfortunately, in some cases I did pose a risk to the repertoires of identity of my respondents. Despite a steady increase in the number of people in Namibia using HIV testing facilities and the growing number of people who go public about their HIV status, there is still a veil of secrecy that often surrounds these issues. One respondent who did not want to go public about his status but who had told me that he was living with HIV would joke "I'm going home for my ' $t$ ", or "I've already had my ' $t$ ' this morning", knowing people within earshot would assume he was talking about drinking tea rather than tablets. In this case the openness between us made it easier to avoid any unintentional disclosure. In other cases my relationship with respondents had not attained the same degree of openness and supporting their projects of impression management involved more guesswork. Whilst I did not want do put people's repertoires of identity at risk by accidentally "outing" them, I was also aware that if I overstated the centrality of HIV/AIDS in my research I would probably lose quite a number of respondents. Furthermore, as it was not absolutely necessary to know about respondents' HIV status for my research, I wanted to adhere to a principle of voluntary disclosure.

Even when acting with a high degree of care and attention, there remains the element of chance: Hamutenya's encounter with my research assistant in the hospital; the presence of the AIDS activist when we were visiting Selina. My research assistants 
and I sought to mitigate these risks through the way in which we presented the research in the settlements. We emphasised that it was about community groups and that, because of the scale of the HIV/AIDS epidemic, there were of course a lot of groups working on this topic. In describing the groups that we worked with we would always point out that some of them had no obvious connection to HIV/AIDS, like the brick-making project or the Local Development Committees. We wanted to ensure that respondents could describe our research without recourse to phrases like "this disease of today" (a common euphemism for HIV/AIDS ), so that we could be a positive rather than a negative identity prop. From the fact that only four people withdrew from the study I would suggest that this approach was fairly successful.

\section{Concluding remarks}

The aim of this paper has been to share my thoughts on two ethical issues that arose from early field observations. I will conclude with some reflections on how the emergence of these issues highlighted certain limitations in my ethical approach.

I have described how relationships that emerged between colleagues, respondents, other acquaintances and I were drawn on in the processes of identity negotiation. In recognising myself as an identity prop, I have attributed a form of agency to myself that I had not addressed when writing my ethical approach. This is a complex type of agency because the way in which it is manifested is often unintentional. However, whilst the outcomes are not always intentional they are relatively predictable, and it is therefore reasonable to demand that I take responsibility for seeking to minimise the potential for harm.

The ethical approach that I formulated prior to starting my fieldwork seemed to be inadequate for this task. In fact, it seemed rather formulaic. There were two limitations that stood out. Firstly, my ethical approach focused quite narrowly on technical issues around my research activities and the formal processes of generating, storing and analysing data, but said very little about the respondents as persons pursuing their own personal projects and objectives. Although I had devoted considerable attention to how issues of dependency and limited agency might affect my recruitment and consent procedures, I had made no comments about how respondents might use their agency to capitalise on the positive and mitigate the negative symbolic values that could be derived from their relationships with me. This suggests a second limitation, which is in part derived from the way that the ethical clearance application was structured. The emphasis on technical issues such as consent and confidentiality oriented my ethical approach almost entirely around the particular relationship between the researcher and the respondent. In doing so, it failed to take into account the web of relationships outside of or on the periphery of formal research activities into which the researcher is woven during extended periods of fieldwork. This might suggest that generic social science ethical procedures require adaptation if they are to be suitable for ethnographic research.

During fieldwork I sought to adapt my ethical approach to accommodate these limitations. In particular, I took a broader view of what constituted research ethics, reflecting the recognition that my research activities were embedded in a system of social relations of which I was also a part. This meant trying to avoid thinking about "research activities" in isolation from the rest of daily life, and recognising the way people might use their relationship with me in their dealings with other people. Whilst 
concerns remained that we would inadvertently fail the "do no harm" principle, my research assistants and I took an increasingly reflexive approach to our position within the life of the settlements and sought to adapt our relationships accordingly.

Based on the discussion in this paper, I would recommend that researchers planning extended periods of fieldwork give more consideration in their ethical approaches than I did to the relationships that can emerge at the periphery of their formal research. I would also recommend that during ethical clearance procedures research students are encouraged to take a more imaginative and holistic approach to ethics that takes into consideration the wider community-level processes of identity construction and negotiation, rather than limiting their scope to the direct relationship between the researcher and the respondent.

\section{References}

Campbell, C. and S. Jovchelovitch. 2000. Health, community and development: Towards a social psychology of participation. Journal of Community \& Applied Social Psychology 10(4), 255-270.

Cinnirella, M. 1998. Exploring temporal aspects of social identity: The concept of possible social identities. European Journal of Social Psychology 28(2), 227248.

Davis, D. 1986. Changing self-image in Newfoundland. In Self, sex, and gender in cross-cultural fieldwork, eds. T. L. Whitehead and M. E. Conaway, 240-262. Chicago: University of Illinois Press.

Dunning, E. 1999. Sport matters: Sociological studies of sport, violence and civilization. London: Routledge.

Fumanti, M. 2002. Small town elites in northern Namibia: The complexity of class formation in practice. In Namibia: Society, sociology, eds. V. Winterfeldt, T. Fox and P. Mufune, 169-177. Windhoek: University of Namibia.

Howarth, C. 2002. Using the theory of social representations to explore difference in the research relationship. Qualitative Research 2, 21-33.

Jovchelovitch, S. 1996. In defence of representations. Journal of the Theory of Social Behaviour 26, 121-135.

Langer, S. 2005. Protecting patients-managing persons. Anthropology Matters 7(1) (www.anthropologymatters.com/journal).

Mookherjee, N. 2001. Dressed for fieldwork: Sartorial borders and negotiations. Anthropology Matters 3 (www.anthropologymatters.com/journal).

Moscovici, S. 1984. The phenomenon of social representations. In Social representations, eds. R. M. Farr and S. Moscovici, 3-70. Cambridge: Cambridge University Press.

Office of the President. 2004. Namibia vision 2030. Windhoek: AIM Publications.

Schensul, J.J., M.D. LeCompte, R.T. Trotter II, E.K. Cromley, and M. Singer. 1999. Mapping social networks, spatial data, and hidden populations. Walnut Creek: AltaMira Press. 
Srivastava, P. 2006. Reconciling multiple researcher positionalities and languages in international research. Research in Comparative and International Education 1, 210-222.

Wagner, W., G. Duveen, R.M. Farr, S. Jovchelovitch, F. Lorenzi-Cioldi, I. Marková and D. Rose. 1999. Theory and method of social representations. Asian Journal of Social Psychology 2, 95-125.

\section{Acknowledgments}

I would like to acknowledge the comments and suggestions made by my research assistants throughout the fieldwork period, as well as those of Janet Seeley, Steve Russell and two anonymous reviewers.

\section{About the author}

Joel Busher's main interest is in the processes through which responses to long-wave events re-configure social relationships and community-level power structures. His doctoral research explores experiences of "the fight against HIV/AIDS" in Namibia and the way in which these have affected notions of civil participation, social responsibility, moral cohesion and trust. He can be contacted at j.busher@uea.ac.uk 